\title{
Patch Testing with Various Mango (Mangifera indica) Extracts
}

\author{
Hsuan-Hsiang Chen* and Chee-Ching Sun \\ Department of Dermatology, National Taiwan University Hospital and National Taiwan University College of Medicine, Taipei, Taiwan
}

\begin{abstract}
Received: 10 June, 2014; Accepted: 14 July, 2014; Published: 28 July2014
*Corresponding author: Hsuan-Hsiang Chen, MD, Department of Dermatology, National Taiwan University Hospital, 7, Chung-Shan South Road, Taipei, Taiwan, Tel.: +886-2-2356-2141; Fax: +886-2-2393-4177; E-mail address: beauty101@gmail.com
\end{abstract}

\begin{abstract}
People in Taiwan often complain that their skin condition worsened after consuming mango. We used a systemic approach to evaluate various type IV hypersensitivities induced by various mango preparations. A total of 12 preparations were made from different extracts derived from two varieties of mango, for the patch test. Two groups totaling 179 cases were patch tested. The peel and peel-lining from both types of mango similarly trigger most of the allergic responses, and most of positive cases reacted to mango in ether preparations. Therefore, a $10 \%$ ether extract could be used as a simple and standard preparation for testing mango allergy in suspected patients.
\end{abstract}

Keywords: Mango dermatitis; Patch test

\section{Introduction}

The mango is one of the major corps in Taiwan. In addition to the indigenous variety, numerous varieties have been introduced from abroad. The native variety, called the "small mango" or "green mango", was brought to Taiwan from India in 1561. Around 1900, other varieties were imported from Indonesia and the Philippines. In 1954, several varieties such as the "Big mango" or "Apple mango" were introduced from Florida, Hawaii, and Puerto Rico.

Every year during the mango season in Taiwan, patients often complain, without any actual proof, that their skin condition worsen because of having eaten mango, especially small mangos. This assertion is so prevalent that the possibility of contact allergic reaction to mango needs to be investigated.

We conducted a comparative study using various mango extracts to evaluate the possibility of type IV allergic contact dermatitis to mango.

\section{Methods}

Two types of mangos were used for patch testing: one was the native green variety weighing about $150 \mathrm{gm}$, and the other was an Apple-red American variety (Haden), weighing about $350 \mathrm{gm}$.

The mangos were subdivided into 3 parts: the peel, the peellining and juicy pulp from the fruit. Extracts were prepared in the following way: 20 gm of finely ground mango material from each part was agitated for 2 hours in $100 \mathrm{ml}$ of ether. The suspension was filtered and the filtrate was again mixed with $100 \mathrm{ml}$ of ether. Both ether portions were combined and the extracts were concentrated in a vacuum rotary evaporator to about $20 \mathrm{ml}$ and stored at $4^{\circ} \mathrm{C}$. For patch testing, the extracts were diluted to $10 \%$ with ether. Aqueous extracts were also prepared in a similar way. A total of 12 preparations were made for the patch test.

Two groups totaling 179 cases were patch tested with the 12 mango preparations. One group (93 cases) was from the Contact Clinic of National Taiwan University Hospital and had itchy dermatitis on the face and hands, possibly due to eating mangos. The control group (86 cases) consisted of dermatologic in-patients with non-eczematous diseases.

\section{Results}

Out of the 179 cases, 12 patches tested positive. (Table 1). Eleven of these were from the Contact Clinic group. In the In-patient control group only one case was positive. The age distribution of patients patch tested was listed in Table 2. Six out of the 11 cases from the Contact Clinic group were in the 11-20 age group. The incidence for males in the Contact Clinic group was $21.1 \%$ while in the in-patient group it was $0 \%$. The incidence for females was $5.5 \%$ in the Contact Clinic group, and $2.1 \%$ in the in-patient group.

Most of these cases reacted to mango in ether preparations (Tables 3 and 4). Out of the 10 cases which were positive to the small mango peel, 7 were also positive to the big mango peel. There were

Table 1: Number of patients patch tested with mango extracts.

\begin{tabular}{|l|c|c|c|c|}
\hline \multirow{2}{*}{} & & Tested (179) & Positive (12) & $\begin{array}{c}\text { Percentage } \\
\text { Distribution } \\
\text { (\%) }\end{array}$ \\
\hline \multirow{2}{*}{$\begin{array}{l}\text { Contact Clinic } \\
\text { patients }\end{array}$} & $\mathrm{M}$ & 38 & 8 & 21.1 \\
\cline { 2 - 5 } & $\mathrm{F}$ & 55 & 3 & 5.5 \\
\cline { 2 - 5 } & Total & 93 & 11 & 11.8 \\
\hline \multirow{2}{*}{$\begin{array}{l}\text { In-patient } \\
\text { controls }\end{array}$} & $\mathrm{M}$ & 38 & 0 & 0 \\
\cline { 2 - 5 } & $\mathrm{F}$ & 48 & 1 & 2.1 \\
\cline { 2 - 5 } & Total & 86 & 1 & 1.2 \\
\hline
\end{tabular}

M: Male patients

F: Female patients

Percentage distribution: Total positive cases in the two groups (in percentage) 
3 positives to the peel-lining of each type of mango. Only 2 cases reacted to the juicy pulp. One case reacted to all three parts of both the big and small mango in ether. Of the cases which reacted to the peel in ether, only 2 were positive to the peel in aqueous.

Among the 11 cases from the Contact Clinic group, 6 exhibited dermatitis on the face, 5 on the arm, 3 on the neck, 2 on the hands and 2 on the ears.

\section{Discussions}

"Mango dermatitis" is the common term given to allergic contact dermatitis to the sap or skin of the fruit of Mangifera indica, a member of the Anacardiaceae family, which includes such well-known plants and trees as poison ivy, sumac, cashew, and pistachio. The rind of the mango contains a catechol (cardol) similar to the catechol (urushiol) of the poison ivy group. [1] Although these substances are irritants, various allergic responses can be triggered by different mango preparations. Type IV allergic contact dermatitis in sensitized patients can be caused by the oleoresin of the mango tree sap or the skin of the fruit, or allergic cheilitis from eating mango. [2] Besides, type I anaphylactic reaction can follow ingestion of mango. [3-5] Miell et al. used prick test with mango juice $(0.1 \mathrm{ml})$, melon juice $(0.1 \mathrm{ml})$, mango juice $(0.1 \mathrm{ml}$ diluted one in 10 with physiological saline), and physiological saline as the diagnostic tool for type I anaphylactic reaction without patch tests in their report [5].

Different from the anaphylactic reaction, every year during the mango season in Taiwan, patients often complain, without any actual proof, that their skin condition deteriorated due to mango consumption (especially small mangoes). According to the description and clinical manifestation, this skin problem may be caused by type IV allergic response, rather than type I reaction. Calvert et al. [6] reported four cases of mango dermatitis confirmed by patch testing to a series composed of sap (diluted in paraffin 1 in 100, 1 in 10 and neat), crushed leaf, crushed stem and fruit skin. In this report, diagnostic patch testing for mango dermatitis did not include the flesh (the juicy pulp) or the flesh immediately below the skin surface (the peel-lining). Although Weinstein et al. [7] later reported that the $5 \mathrm{~mm}$ of flesh under the skin contains enough penetrated antigen to elicit a positive response in sensitized individuals, this reports described patch tests with the outer peel only, instead of systemically testing the various components. The Browns [8] also reported a case of mango dermatitis with patch testing by extracting the pulp and peel of six mangoes separately with anhydrous ether in a Soxhlet apparatus. However, they did not include the peel-lining, nor did they systematically explore on the allergic results of different extracts of various parts of the mango fruit in a larger number of subjects.

In this report, we tried to use a systemic approach to evaluate type IV contact hypersensitivity induced by various mango preparations. A number of conclusions can be drawn from this study. First, the ether extract contains the most allergenic components of the mango. A $10 \%$ ether extract could be used as a simple and standard preparation for testing mango allergy in suspected patients. Second, the mango peel seems to be a potent sensitizer. The peel-lining can also trigger allergic response. Therefore, by avoiding contact with the peel when preparing and eating mangos, most cases with mango dermatitis should still be able to enjoy mangos. Third, the corresponding parts of each type of mango (the small green mango and the big apple mango) show a similar sensitizing potency. The popular myth that the skin condition worsened because of mango consumption, especially small mangos, is not correct.

A relationship between sensitivity to poison oak or poison ivy and mango dermatitis has been suggested. Hershko et al. [9] have discussed that acute allergic contact dermatitis can arise on first exposure to mango in patients who have been sensitized beforehand by contact with other urushiol-containing plants.

Table 2: Age distribution of the patients subjected to patch test.

\begin{tabular}{|c|c|c|c|c|c|c|c|}
\hline \multirow[b]{2}{*}{ Age group } & \multicolumn{3}{|c|}{ Contact Clinic patients: $\mathrm{N}=93$} & & \multicolumn{3}{|c|}{ In-patients controls: $\mathbf{N}=\mathbf{8 6}$} \\
\hline & Sex & No. tested & No. positive & & No. tested & No. positive & $\%$ \\
\hline $0-10$ & $\begin{array}{l}\mathrm{M} \\
\mathrm{F}\end{array}$ & $\begin{array}{l}0 \\
1\end{array}$ & $\begin{array}{l}0 \\
0\end{array}$ & & $\begin{array}{l}2 \\
2 \\
\end{array}$ & $\begin{array}{l}0 \\
0\end{array}$ & \\
\hline $11-20$ & $\begin{array}{l}\mathrm{M} \\
\mathrm{F}\end{array}$ & $\begin{array}{c}10 \\
5\end{array}$ & $\begin{array}{l}6 \\
0\end{array}$ & & $\begin{array}{l}5 \\
3\end{array}$ & $\begin{array}{l}0 \\
0\end{array}$ & \\
\hline $21-30$ & $\begin{array}{l}\mathrm{M} \\
\mathrm{F}\end{array}$ & $\begin{array}{c}7 \\
27 \\
\end{array}$ & $\begin{array}{l}0 \\
2\end{array}$ & & $\begin{array}{l}5 \\
9\end{array}$ & $\begin{array}{l}0 \\
0\end{array}$ & \\
\hline $31-40$ & $\begin{array}{l}\mathrm{M} \\
\mathrm{F}\end{array}$ & $\begin{array}{l}2 \\
4\end{array}$ & $\begin{array}{l}1 \\
0\end{array}$ & & $\begin{array}{l}4 \\
9\end{array}$ & $\begin{array}{l}0 \\
0\end{array}$ & \\
\hline $41-50$ & $\begin{array}{l}\mathrm{M} \\
\mathrm{F}\end{array}$ & $\begin{array}{l}8 \\
5\end{array}$ & $\begin{array}{l}1 \\
1\end{array}$ & & $\begin{array}{l}3 \\
9 \\
\end{array}$ & $\begin{array}{l}0 \\
1\end{array}$ & \\
\hline $51-60$ & $\begin{array}{l}\mathrm{M} \\
\mathrm{F}\end{array}$ & $\begin{array}{c}5 \\
11 \\
\end{array}$ & $\begin{array}{l}0 \\
0\end{array}$ & & $\begin{array}{c}9 \\
11 \\
\end{array}$ & $\begin{array}{l}0 \\
0\end{array}$ & \\
\hline $61-$ & $\begin{array}{l}\mathrm{M} \\
\mathrm{F}\end{array}$ & $\begin{array}{l}6 \\
2 \\
\end{array}$ & $\begin{array}{l}0 \\
0\end{array}$ & & $\begin{array}{c}10 \\
5\end{array}$ & $\begin{array}{l}0 \\
0\end{array}$ & \\
\hline Total & $\begin{array}{l}\mathrm{M} \\
\mathrm{F}\end{array}$ & $\begin{array}{l}38 \\
55\end{array}$ & $\begin{array}{l}8 \\
3\end{array}$ & $\begin{array}{c}21.1 \\
5.5\end{array}$ & $\begin{array}{l}38 \\
48\end{array}$ & $\begin{array}{l}0 \\
1\end{array}$ & 2.1 \\
\hline
\end{tabular}

M: Male patients

F: Female patients

Percentage distribution: Total positive cases in the two groups (in percentage) 
Table 3: Positive patch test results of various mango extracts prepared from small green mango and big apple mango.

\begin{tabular}{|l|c|c|c|}
\hline & \multicolumn{2}{|c|}{ Small green mango } & \multicolumn{2}{|c|}{ Big apple mango } \\
\hline & Ether & Aqueous & Ether \\
\hline Peel & 10 & 2 & 7 \\
\hline Peel-lining & 3 & 0 & 3 \\
\hline Juicy pulp & 1 & 0 & 0 \\
\hline
\end{tabular}

Table 4: Comparative analysis of various mango extracts that triggered positive patch tests in the patients.

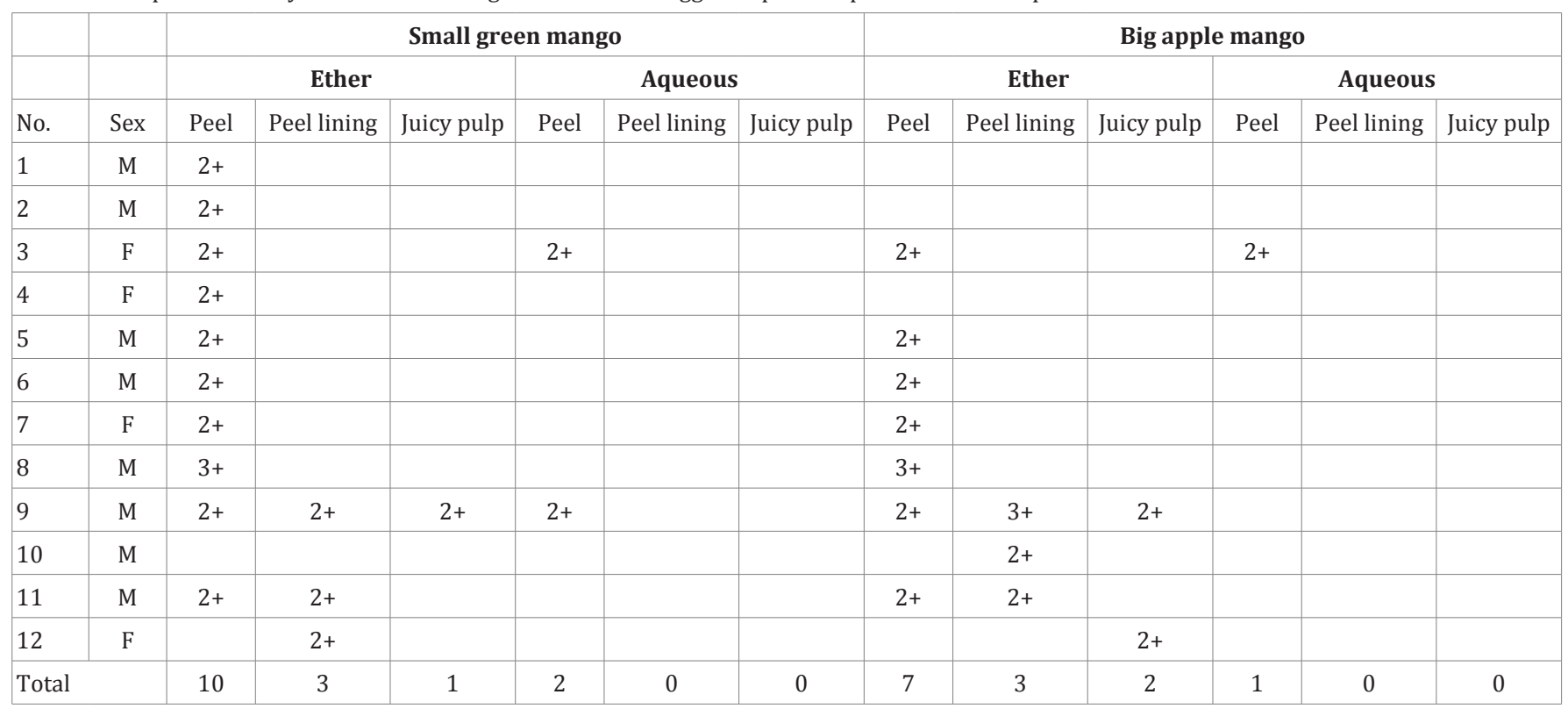

M: Male patients

F: Female patients

The cross reactivity between poison oak, poison ivy, mango and other plants of the Anacardiaceae family, genus Toxicodendron, is thought to relate to the presence of alk(en)ylcatechols (i.e. urushiol) in these plants. Recently, Oka et al. reported 3 resorcinol derivatives: heptadecadienyl resorcinol, heptadecenyl resorcinol and pentadecyl resorcinol (collectively named 'mangol'), as mango allergens [10]. They extracted the first 'two' components (heptadecadienyl resorcinol and heptadecenyl resorcinol) from the Philippine mango, adjusted them to $0.05 \%$ concentration in petrolatum and patch tested the components on two subjects with mango dermatitis. They concluded that heptadec(adi)enyl resorcinols could elicit positive patch test reactions in mango-sensitive patients. As the chemical structures of allergens belonging to the Anacardiaceae family, are "alkyl or alkenyl catechols" and "alkyl or alkenyl resorcinols", the alkyl or alkenyl group might be recognized as an "epitope" that acts as common allergen.

We did not explore the possibility of cross reactions between previous urushiol-containing plant contact history and mango dermatitis, therefore it is not clear whether our patients have been sensitized beforehand by contact with other Anacardiaceae family plants. We suggested that the allergic reactions between catechols and resorcinols should be further investigated.

\section{References}

1. Robert L, Rietschel and Joseph F, Fowler Jr. Allergic Sensitization to Plants. In: Fisher's contact dermatitis. 5th edition. Philadelphia, 2001, Lippincott Williams \& Wilkins. p 352.

2. Thoo $\mathrm{CH}$, Freeman S. Hypersensitivity reaction to the ingestion of mango flesh. Australas J Dermatol 2008; 49(2):116-9.

3. Rubin JM, Shapiro J, Muehlbauer P, Grolnick M. Shock reaction following ingestion of Mango. JAMA 1965; 193(5): 397.

4. Dang RW, Bell DB. Anaphylactic reaction to the ingestion of mango. Hawaii Med J 1967; 27: 149

5. Miell J, Papouchado M, Marshall AJ. Anaphylactic reaction after eating a mango. BJD 1988; 297: 1639-1640.

6. Calvert ML, Robertson I, Samaratunga H. Mango dermatitis: allergic contact dermatitis to Mangifera indica. Austrlas J Dermatol 1996; 37: 59-60.

7. Weinstein S, Bassiri-Tehrani S, Cohen DE. Allergic contact dermatitis to mango flesh. Int J Dermatol 2004; 43: 195-6

8. Brown A, Brown F. Mango dermatitis. J Allergy 1941; 12: 310-311.

9. Hershko K, Weinberg I, Ingber A. Exploring the mango-poison ivy connection: the riddle of discriminative plant dermatitis. Contact Dermatitis. 2005; 52(1):3-5.

10. Oka K, Saito F, Yasuhara T, Sugimoto A. A study of cross-reactions between mango contact allergens and urushiol. Contact Dermatitis. 2004; 51(5-6):292-6. 